\title{
A Novel Continuous Extrusion Process to Fabricate Wedge-Shaped Light Guide Plates
}

\author{
Wen-Tse Hsiao, ${ }^{1}$ Jui-Chang Lin, ${ }^{2}$ Keng-Shiang Huang, ${ }^{3}$ Chih-Hui Yang, ${ }^{3}$ \\ Alexandru Mihai Grumezescu, ${ }^{4}$ Shih-Feng Tseng, ${ }^{1}$ and Yung-Sheng Lin ${ }^{2}$ \\ ${ }^{1}$ Instrument Technology Research Center, National Applied Research Laboratories, Hsinchu 30076, Taiwan \\ ${ }^{2}$ Hungkuang University, Taichung 43302, Taiwan \\ ${ }^{3}$ I-Shou University, Kaohsiung 82445, Taiwan \\ ${ }^{4}$ University Politehnica of Bucharest, 060042 Bucuresti, Romania
}

Correspondence should be addressed to Yung-Sheng Lin; linys@sunrise.hk.edu.tw

Received 24 May 2013; Accepted 19 October 2013

Academic Editor: Peng He

Copyright (c) 2013 Wen-Tse Hsiao et al. This is an open access article distributed under the Creative Commons Attribution License, which permits unrestricted use, distribution, and reproduction in any medium, provided the original work is properly cited.

\begin{abstract}
Backlight modules are key components in thin-film transistor liquid crystal displays (TFT-LCD). Among the components of a backlight module, the light guide plate (LGP) plays the most important role controlling the light projected to the eyes of users. A wedge-shaped LGP, with its asymmetrical structure, is usually fabricated by an injection proces, but the fabrication time of this process is long. This study proposes a continuous extrusion process to fabricate wedge-shaped LGPs. This continuous process has advantages for mass production. Besides a T-die and rollers, this system also has an in situ monitor of the melt-bank that forms during the extrusion process, helping control the plate thickness. Results show that the melt bank has a close relationship with the plate thickness. The temperature of the bottom heater and roller was adjusted to reduce the surface deformation of the wedge-shaped plate. This continuous extrusion system can successfully manufacture wedge-shaped LGPs for mass production.
\end{abstract}

\section{Introduction}

All displays without self-luminance, such as liquid crystal displays (LCDs), use a backlight as a light source. Common backlight modules consist primarily of a light source, a reflector, a light guide plate (LGP), a diffusion film, a prism sheet, a cover sheet, a print circuit board, and a drive circuit. The LGP, also called the backlight plate, is the most important component of the backlight module because it integrates all other components to control the backlight source path.

Poly(methylmethacrylate) (PMMA) material has excellent properties of optical transmittance, low weight, low cost, and easy processing. These features make PMMA useful in many applications, such as LCD backlight display panels, lens optics, optical fibers, and other photoelectric components, devices, and applications. Therefore, PMMA can replace traditional glass materials as the main material of LPGs. Kim [1] investigated a mechanism of warping behavior for PMMA diffusing plate. To avoid warpage of a diffuser plate, the various different composite glass fiber contents were adjusted. Results indicate that the warpage of the diffusing plate was reduced by using PMMA composites modified with glass fiber. Moreover, the thermal and optical properties such as thermophysical, diffusing characteristics, and uniformity were also improved. Tagaya et al. [2] demonstrated the advanced highly scattering optical transmission polymer backlight. Based on the reflection and refractive and lightscatting theory, the LGP with microprism structures was designed. This backlight exhibited approximately three times higher luminance and $20 \%$ efficiency than conventional flattype backlight. Okumura et al. [3] proposed a highly efficient backlight with microspherical particle for thin LCD applications. The modeling simulation program employed a Monte Carlo method based on Mie scattering theory. They can optimize both prismatic condition and multiple scattering characteristics. Compared to the conventional backlight, the proposed model optical efficiency can be enhanced up to $62 \%$ with $0.5 \mathrm{~mm}$ thickness for a 4 -inch panel. Moreover, the light 


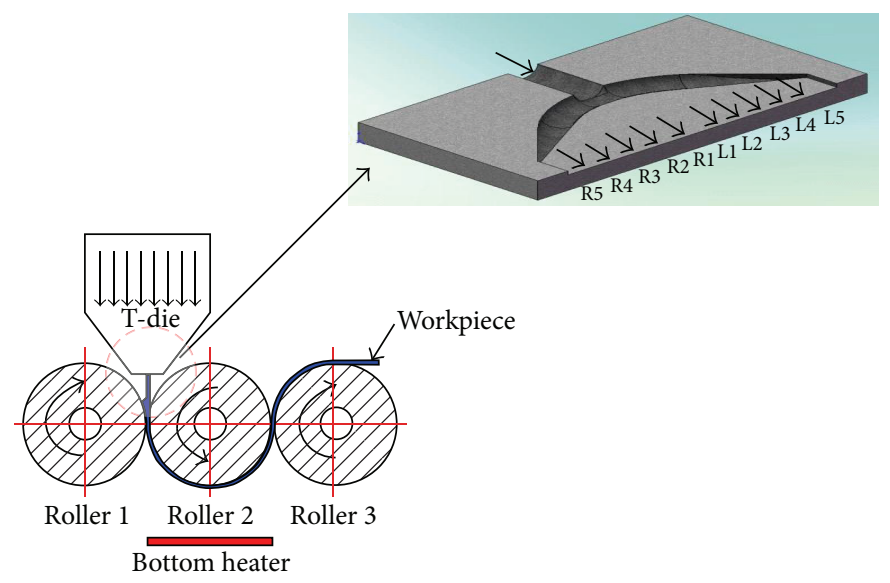

(a)

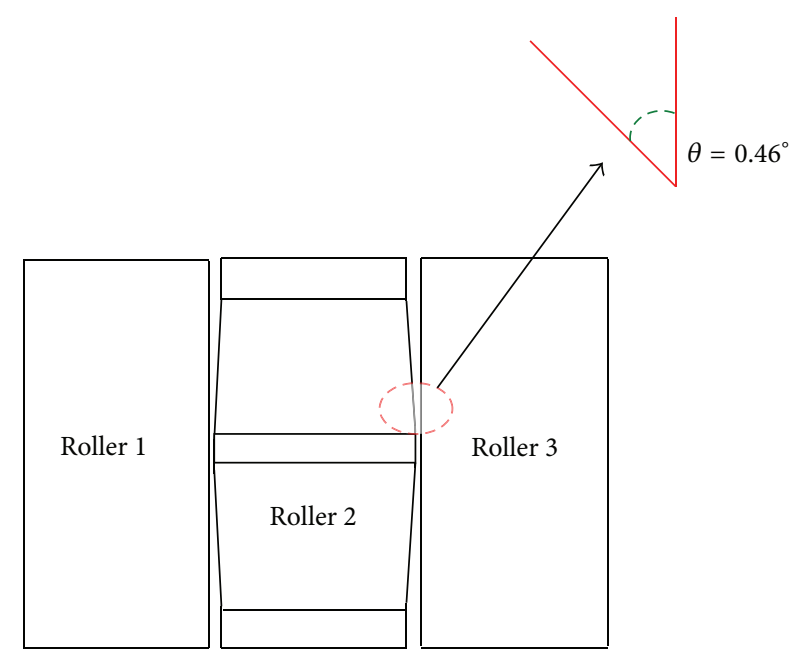

(b)

FIGURE 1: Scheme and illustration of the extrusion system. (a) Side view and (b) top view.

uniformity of brightness can be achieved without using any optical films.

Based on physical appearance, LGPs can be classified as flat plate and wedge-shaped plate. A wedge-shaped plate has the advantages of lighter weight, thinner thickness, reduced power consumption, less heat generation, and improved color uniformity. Therefore, most of the large backlight modules use a wedge-shaped LGP to meet the demands of a large dimension display.

A wedge-shaped plate is usually manufactured using two forming processes: injection molding and hot embossing [4]. Of these two processes, injection molding is the more common method of fabricating wedge-shaped LGPs. The injection compression molding processes adopt an automatic batch mode to conduct open and close movements between the mold and the slide, fabricating three-dimensional structures. To fabricate asymmetrical shapes, it must use different molds and cooling equipment. The major limitation of this injection method is its discontinuous process for mass production. Compared to the injection processing, the extrusion process is a continuous process. The extrusion processes have the advantages of (i) high throughput, (ii) low equipment investment cost, (iii) low labor cost, and (iv) easy automation for fabricating standardized and uniform products [5]. For cost-effective fabrication of large area products, roll-to-roll extrusion process stands for an ideal method [6]. Roll-toroll manufacturing is a very efficient system for web material packaging and storage and has been widely applied in numerous industrial material processes [7]. This process is applicable to many fields such as metal sheets, plastic foils, paper, and textiles $[7,8]$. However, there is no research using roll-toroll extrusion processes to fabricate wedge-shaped light guide plates.

Controlling the processing temperature and pressure is an important issue in producing thin LGPs with large dimensions. The temperature and pressure affect the structural and
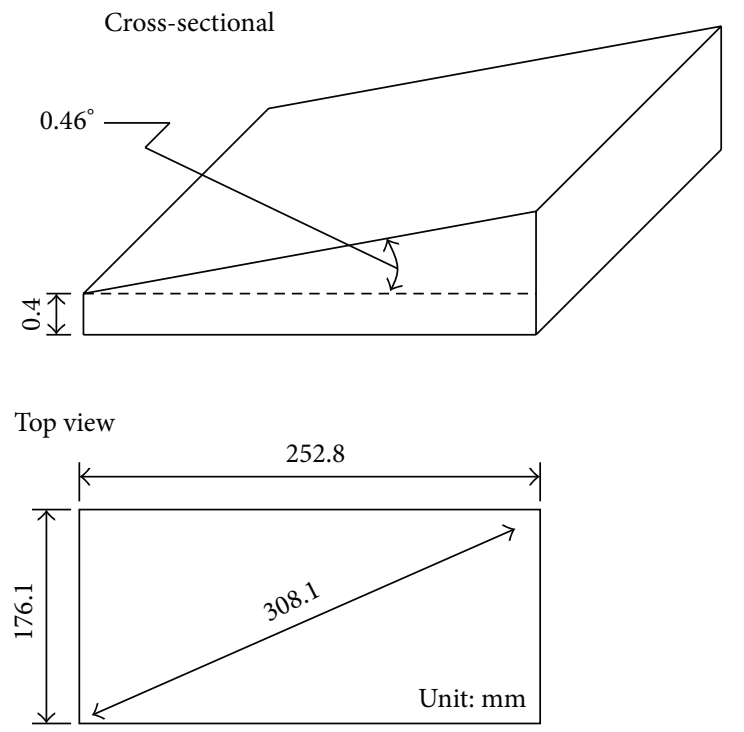

FIGURE 2: Schematic diagram of the standard wedge-shaped LGP.

optical performance characteristics of the product. In an effort to determine the optimal conditions of the molding processes, related studies have discussed the parameters of the injection molding process. Chen et al. [9] used CAE software to simulate the PVT characteristics of plastic optics. Their simulation results show that the temperature distribution affects the shrinkage, deformation, and residual stress of the plastic. Their results can help to predict shrinkage and deformation of the plastic and efficiently control real processing performance. Yang et al. [10] used three-dimensional mold flow theory to derive equations of padding, packing, cooling, and deformation in the injection forming processes. They also developed a mathematical model based on the finite volume method to determine the optimization parameters. 


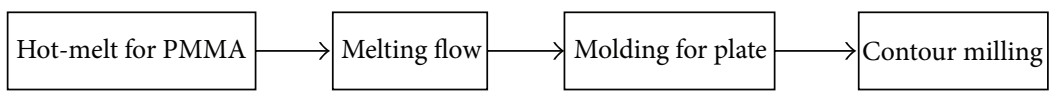

FIGURE 3: Flowchart of the continuous extrusion forming process.

TABLE 1: Specifications of the single screw extrusion machine.

\begin{tabular}{lcc}
\hline Throughput & \multicolumn{2}{c}{$250 \pm 20 \mathrm{~kg} / \mathrm{hr}$} \\
Single screw & Diameter $=7.5 \mathrm{~cm}$, Length $=270 \mathrm{~cm}$ \\
Roller & Precision of temperature & $\pm 1^{\circ} \mathrm{C}$ \\
& Cooling type & Water \\
Bottom heater & Far IR emitter & $220 \mathrm{~V} / 360 \mathrm{~W}$ \\
T-die & Width & $60 \mathrm{~cm}$ \\
& Zone number & 10 \\
\hline
\end{tabular}

TABLE 2: Characteristics of PMMA material.

\begin{tabular}{lc}
\hline Type & SUMIPEX EX \\
\hline Refractive index & 1.49 \\
Total light transmittance $(\%)$ & $>92$ \\
Haze $(\%)$ & $<0.5$ \\
Vicat softening temperature $\left({ }^{\circ} \mathrm{C}\right)$ & 104 \\
Deflection temperature under load $\left({ }^{\circ} \mathrm{C}\right)$ & 99 \\
Melt flow rate $(\mathrm{g} / 10 \mathrm{~min})$ & 1.5 \\
Tensile strength $(\mathrm{MPa})$ & 74 \\
Specific gravity $\left(\mathrm{g} / \mathrm{m}^{3}\right)$ & 1.19 \\
Mold shrinkage $(\%)$ & $0.2-0.6$ \\
Water absorption $(\%)$ & 0.3 \\
\hline
\end{tabular}

TABLE 3: Temperatures of the T-die at different positions.

\begin{tabular}{lccccccccc}
\hline \multicolumn{10}{c}{ Temperature of T-die position $\left({ }^{\circ} \mathrm{C}\right)$} \\
L5 & L4 & L3 & L2 & L1 & R1 & R2 & R3 & R4 & R5 \\
\hline 254 & 256 & 251 & 251 & 250 & 250 & 249 & 249 & 253 & 253 \\
\hline
\end{tabular}

Gissing and Knappe [11] presented a thin plate model and discussed the volume shrinkage rate of the opening mold. In addition, the proposed simple model was used to describe the effects of volume shrinkage, residual stress, and dimension shrinkage. Their results indicate that a long processing time led to smaller shrinkage, and the smaller shrinkage rate could reduce unbalance of the shrinkage.

The literature review in this study only covers the injection molding method of manufacturing LGPs. For the first time, this study uses a continuous extrusion process to fabricate a wedge-shaped LGP. The experiments in this study also test the melt-bank adjustment and system device temperatures to maximize product quality. Using the precise control of the mold flow through a T-die, a 0.46 degree wedge-shaped LGP can be fabricated with ease in mass production.

\section{Experimental Equipment and Test Method}

A single screw extrusion machine (BREYER Gmbh, Germany) was used to fabricate wedge-shaped LGPs and Table 1

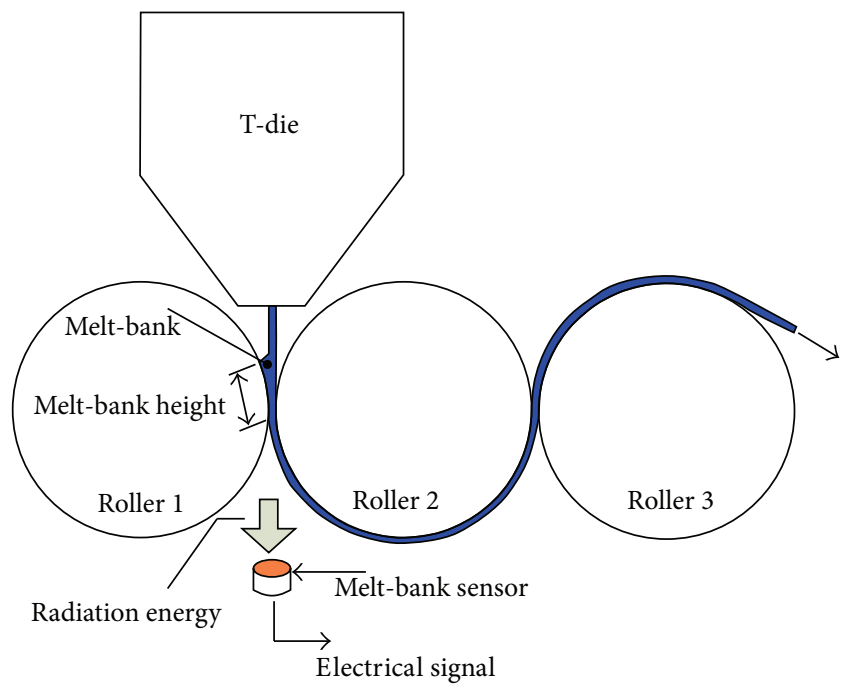

FIGURE 4: Schematic illustration of melt-bank monitoring.

shows the specifications of the extrusion machine. The Tdie was designed to be a symmetrical structure, and different aperture ratios (Figure 1) which can adjust the heating temperatures of different positions (R1 to R5 and L1 to L5) to adapt the nonuniform exit thickness. Figure 1 also indicates the cooling equipment, which consists of three polished rollers. Roller 1 and Roller 3 are cylinders and Roller 2 has a symmetrical trapezoidal shape to form the wedge-shaped plate. To avoid an intense decrease in temperature of melt PMMA, a bottom heater was adapted to control temperatures of the extrusion process to have a uniform pressure distribution.

2.1. Wedge-Shaped LGP Design. Optical-grade PMMA (EX series, Sumitomo Chemical Singapore Pte Ltd.) was used to form wedge-shaped LGPs. Table 2 presents a summary of the material properties of used PMMA. Figure 2 shows the designed dimension of the LGP products in this study. A standard LCD dimension (12.1 in) was used, and the wedgeshaped angle was $0.46^{\circ}$.

2.2. Fabrication Process and Measurement Methods. Figure 3 shows a process flowchart of continuous extrusion-forming. We performed the fabrication process in a climate-controlled room at a constant temperature and humidity $\left(23^{\circ} \mathrm{C}\right.$ and $60 \%$ relative humidity). First, the PMMA material was melted through the T-die and then trundled by Roller 1, Roller 2, and Roller 3 to form the large workpiece. Table 3 shows the fabrication temperatures of T-die to spread the melt PMMA. The temperatures of the bottom heater and Roller 3 were adjusted to investigate the effects of temperature on product deformation. Finally, a milling machine cut off the large 


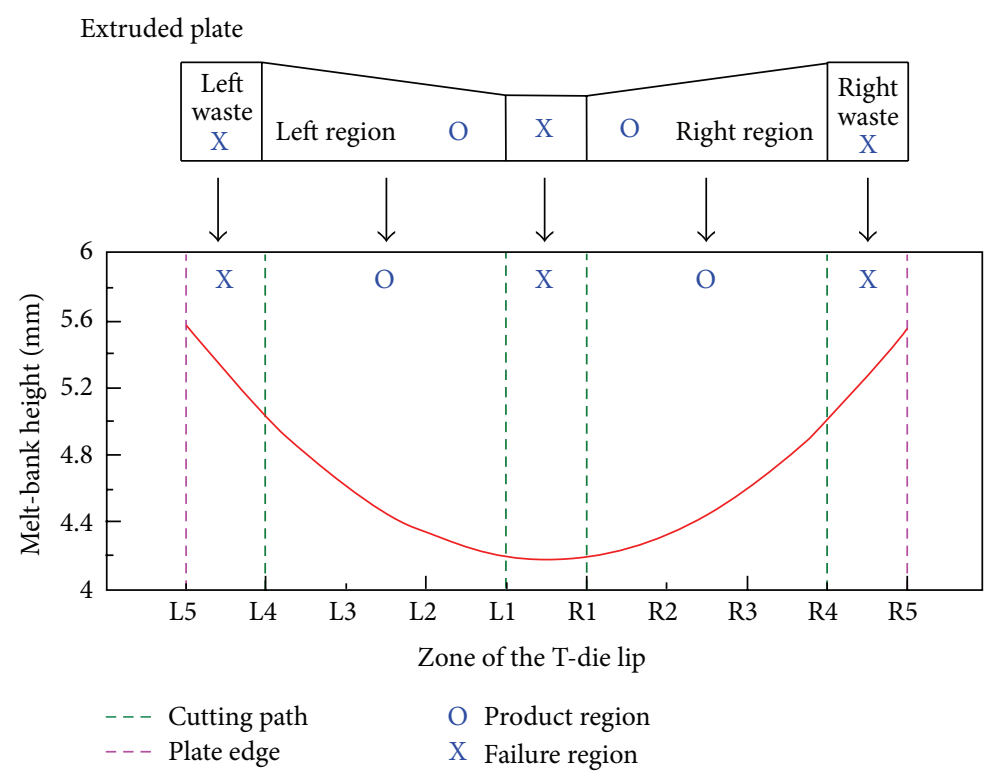

FIGURE 5: Schematic illustrations of the melt-bank height and profile versus positions corresponding to the zone of the T-die lip.

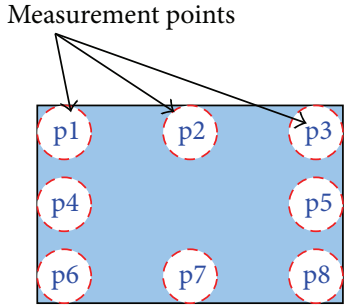

Top view

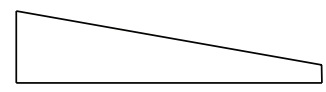

Side view

FIGURE 6: Deformation measurement of the wedge-shaped LGP.

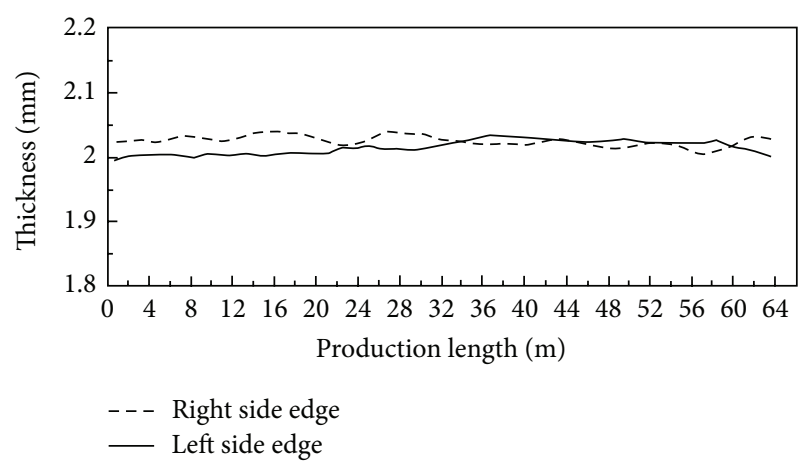

FIGURE 7: Edge thickness variations through the total plate length.

extruded workpiece to obtain LGPs. This fabrication process achieved a production rate of $10.2 \mathrm{pcs} / \mathrm{min}$.

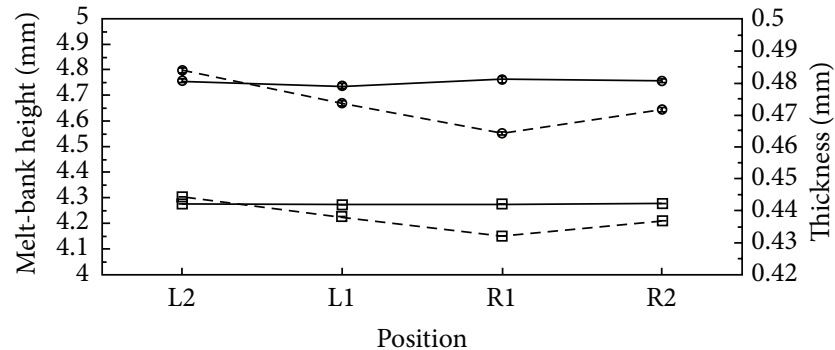

$$
\begin{aligned}
& -\bullet-\text { Melt-bank height (before adjustment) } \\
& \square-\text { Melt-bank height (after adjustment) } \\
& -\bullet-\text { Thin edge thickness (before adjustment) } \\
& \rightarrow \text { Thin edge thickness (after adjustment) }
\end{aligned}
$$

FIGURE 8: Melt-bank height and plate thickness (dashed line: before adjustment, solid-line: after adjustment).

2.2.1. Melt-Bank Monitoring. The melted PMMA materials passing through the high-temperature T-die piled up at the gap between Roller 1 and Roller 2, causing the formation of a melt-bank. The melt-bank plays an important role in the characteristics of manufactured LGPs. The height and profile of the melt-bank were monitored by a temperature sensor. If bank size is large, melt-bank height becomes longer with the decrease in sheet surface temperature. The relationship is acquired by numerical analysis to figure out the melt-bank height based on the measured sheet surface temperature [12]. Figure 4 schematically shows the monitoring in the meltbank.

2.2.2. Definition of the Valid and Invalid Regions of Workpiece. Using the melt-bank monitoring, the relationships of the height and profile of the melt-bank versus the positions could be correlated (Figure 5). The contour of the workpiece 
TABLE 4: Edge deformation values under different temperatures of the bottom heater and Roller 3 (Unit: $\mathrm{mm}$ ).

\begin{tabular}{|c|c|c|c|c|c|c|c|c|c|}
\hline \multirow{3}{*}{ Roller 3} & \multicolumn{9}{|c|}{ Bottom heater } \\
\hline & \multicolumn{3}{|c|}{$130^{\circ} \mathrm{C}$} & \multicolumn{3}{|c|}{$140^{\circ} \mathrm{C}$} & \multicolumn{3}{|c|}{$150^{\circ} \mathrm{C}$} \\
\hline & 0 & $>-0.5$ & $+0.5^{*}$ & 0 & 0 & +0.3 & 0 & 0 & $\overline{+0.1}$ \\
\hline \multirow[t]{3}{*}{$100^{\circ} \mathrm{C}$} & $>-0.5$ & & +0.5 & $>-0.5$ & & +0.25 & $>-0.5$ & & 0 \\
\hline & 0 & $>-0.5$ & +0.5 & 0 & +0.2 & +0.3 & 0 & 0 & 0 \\
\hline & 0 & -0.5 & +0.5 & 0 & -0.5 & +0.3 & 0 & -0.4 & 0 \\
\hline \multirow[t]{3}{*}{$110^{\circ} \mathrm{C}$} & -0.5 & & +0.5 & -0.5 & & +0.2 & -0.45 & & 0 \\
\hline & 0 & -0.5 & $>+0.5$ & 0 & -0.45 & +0.15 & 0 & -0.4 & 0 \\
\hline & 0 & -0.3 & +0.5 & 0 & -0.2 & +0.2 & 0 & -0.2 & 0 \\
\hline \multirow[t]{3}{*}{$115^{\circ} \mathrm{C}$} & -0.1 & & +0.5 & 0 & & +0.1 & 0 & & -0.1 \\
\hline & 0 & -0.3 & $>+0.5$ & 0 & -0.1 & +0.1 & 0 & -0.2 & 0 \\
\hline & 0 & -0.1 & $>+0.5$ & +0.1 & 0 & +0.2 & 0 & 0 & 0 \\
\hline \multirow[t]{2}{*}{$120^{\circ} \mathrm{C}$} & +0.2 & & +0.5 & +0.1 & & +0.2 & 0 & & -0.1 \\
\hline & 0 & 0 & $>+0.5$ & 0 & 0 & +0.2 & +0.1 & 0 & 0 \\
\hline
\end{tabular}

${ }^{*}$ The eight values in each combination of the bottom heater and Roller 3 are the measure results corresponding to the positions from p1 to p8 in Figure 6 , respectively.

obtained after Roller 3 agreed with the profile of the meltbank. We removed the central and side regions of the resulting workpiece to obtain a smooth region as an LGP product. As Figure 5 shows, "X" represents the invalid regions, "O" represents the valid regions, and the dashed line indicates the milling cut-off path.

2.2.3. Edge Thickness Measurement. To test the stability of this continuous extrusion process, we measured the edge thickness of the extruded workpiece. A digital micrometer (Mitutoyo, Tokyo, Japan) with an accuracy of $0.01 \mathrm{~mm}$ was used to measure the edge thickness. The total length of the obtained workpiece was $64 \mathrm{~m}$. Both side edges of the extruded workpiece were measured.

2.2.4. Deformation Measurement of the Wedge-Shaped LGP. To check the surface property of the wedge-shaped LGP, we measured the surface deformation of LGP products. Figure 6 shows the deformation measurement at eight points (p1-p8) of the wedge-shaped LGP. Each point was measured three times to provide data for an average value. The surface deformation was recorded with a digital micrometer (Mitutoyo, Tokyo, Japan).

\section{Results and Discussion}

3.1. Stability Analysis of Workpiece Thickness. Figure 7 shows the edge thickness variation through the total extruded workpiece length under the fabrication conditions listed in Table 1. Results indicate a variation of less than $0.02 \mathrm{~mm}$ through the $64 \mathrm{~m}$ production length. Therefore, the extrusion process has good stability for a long fabrication time.
3.2. Relationship of the Wedge-Shaped LGP Thin Side versus Melt-Bank. The melt-bank plays a key role in the manufacture of wedge-shaped LGPs. The distance between T-die and the roller affects the melt-bank height and the associated plate thickness. The melt-bank height and plate thickness increase with this distance. The melt-bank height should be controlled to obtain the same LGP thickness through the production length. The chocker bar and flex lip of the T-die mold can be adjusted to control the melt-bank. The mold has a total of thirty-four adjustment points. Based on the fabrication parameters in Table 1, Figure 8 shows the relationship of meltbank height and wedge-shaped LGP thin side thickness versus measurement points under unadjusted and adjusted conditions. Results indicate that adjusting the T-die mold condition can help achieve a uniform product thickness.

The thickness distribution profile of the extruded plate is similar to the melt-bank height distribution in Figure 5. The designed standard thin part of wedged-shape LGP is $0.4 \mathrm{~mm}$. The measured thickness of the final manufactured LGP is about $0.44 \mathrm{~mm}$. The difference can be reduced by modifying the melt-bank to fit the commercial product in the future.

3.3. Effect of Temperatures on the Deformation. Table 4 summarizes the surface deformation values under different temperatures of the bottom heater and Roller 3. For each temperature condition, the eight deformation values are the measurement results at points p1 to p8 in Figure 6. Results show that the deformation decreases with the increasing temperature of both the bottom heater and Roller 3 . When the bottom heater was fixed at the maximum operating temperature $\left(150^{\circ} \mathrm{C}\right)$ and the temperature of Roller 3 changed from $100^{\circ} \mathrm{C}$ to $120^{\circ} \mathrm{C}$, the deformation decreased as the temperature of Roller 3 increased. A good surface condition with a deformation less than $0.1 \mathrm{~mm}$ was obtained when Roller 3 was set at 
$120^{\circ} \mathrm{C}$. Experimental results demonstrate that this decrease in deformation can be achieved by increasing the temperatures of the bottom heater and of Roller 3 .

\section{Conclusions}

This study proposes a continuous extrusion process for fabricating wedge-shaped LGPs at a high production rate. The proposed approach has the advantages of a short cycle time, mass production, an easily controlled process, low cost, simple mold design, and precision in the product thickness. The melt-bank is a crucial factor in processing adjustments because it affects the properties of LGPs. Various thicknesses of LGPs can be obtained by adjusting the melt-bank condition. The deformation control can be adjusted by changing the temperatures of the bottom heater and Roller 3. Finally, a wedge-shaped LGP with an angle of 0.46 degrees and surface deformation of less than $0.1 \mathrm{~mm}$ were successfully fabricated using this approach.

\section{Conflict of Interests}

The authors declare that they have no competing interests.

\section{Acknowledgments}

This work was supported by a grant from the National Science Council of Taiwan (NSC 102-2622-E-241-001-CC2) and MG+4C Vertical Integration Enhancement Project between Industries and Academia at Science Parks (no. 102MG06).

\section{References}

[1] G. Kim, "A PMMA composite as an optical diffuser in a liquid crystal display backlighting unit (BLU)," European Polymer Journal, vol. 41, no. 8, pp. 1729-1737, 2005.

[2] A. Tagaya, S. Ishii, K. Yokoyama, E. Higuchi, and Y. Koike, "The advanced highly scattering optical transmission polymer backlight for liquid crystal displays," Japanese Journal of Applied Physics, vol. 41, no. 4, pp. 2241-2248, 2002.

[3] T. Okumura, A. Tagaya, Y. Koike, M. Horiguchi, and H. Suzuki, "Highly-efficient backlight for liquid crystal display having no optical films," Applied Physics Letters, vol. 83, no. 13, pp. 25152517, 2003.

[4] A. Olsson, O. Larsson, J. Holm, L. Lundbladh, O. Öhman, and G. Stemme, "Valve-less diffuser micropumps fabricated using thermoplastic replication," Sensors and Actuators A, vol. 64, no. 1, pp. 63-68, 1998.

[5] R. Chokshi and H. Zia, "Hot-melt extrusion technique: a review," Iranian Journal of Pharmaceutical Sciences, vol. 3, no. 1, pp. 3-16, 2004.

[6] M. W. Wang, W. C. Lin, and M. H. Lee, "Fabrication of flexible microlens array film using roll-to-roll process," Proceedings of the Institution of Mechanical Engineers B, vol. 227, no. 4, pp. 543550, 2013.

[7] K. S. Chen, K. S. Ou, and Y. M. Liao, "On the influence of roller misalignments on the web behavior during roll-to-roll processing," Journal of the Chinese Institute of Engineers, vol. 34, no. 1, pp. 87-97, 2011.
[8] R. R. Søndergaard, M. Hosel, and F. C. Krebs, "Roll to roll fabrication of large area functional organic materials," Journal of Polymer Science, vol. 51, no. 1, pp. 16-34, 2012.

[9] X. Chen, Y. C. Lam, and D. Q. Li, "Analysis of thermal residual stress in plastic injection molding," Journal of Materials Processing Technology, vol. 101, no. 1, pp. 275-280, 2000.

[10] W.-H. Yang, A. Peng, L. Liu, D. C. Hsu, and R.-Y. Chang, "Integrated numerical simulation of injection molding using true 3D approach," in Proceedings of the Annual Technical Conference (ANTEC'04), pp. 486-490, Chicago, Ill, USA, May 2004.

[11] K. Gissing and W. Knappe, "Optimum holding pressure profile during injection molding of thermoplastics," Kunststoffe, vol. 73, no. 5, pp. 8-10, 1983.

[12] http://www.toshiba-machine.co.jp/en/product/oshidashi/lineup/sheet/monitor.html. 

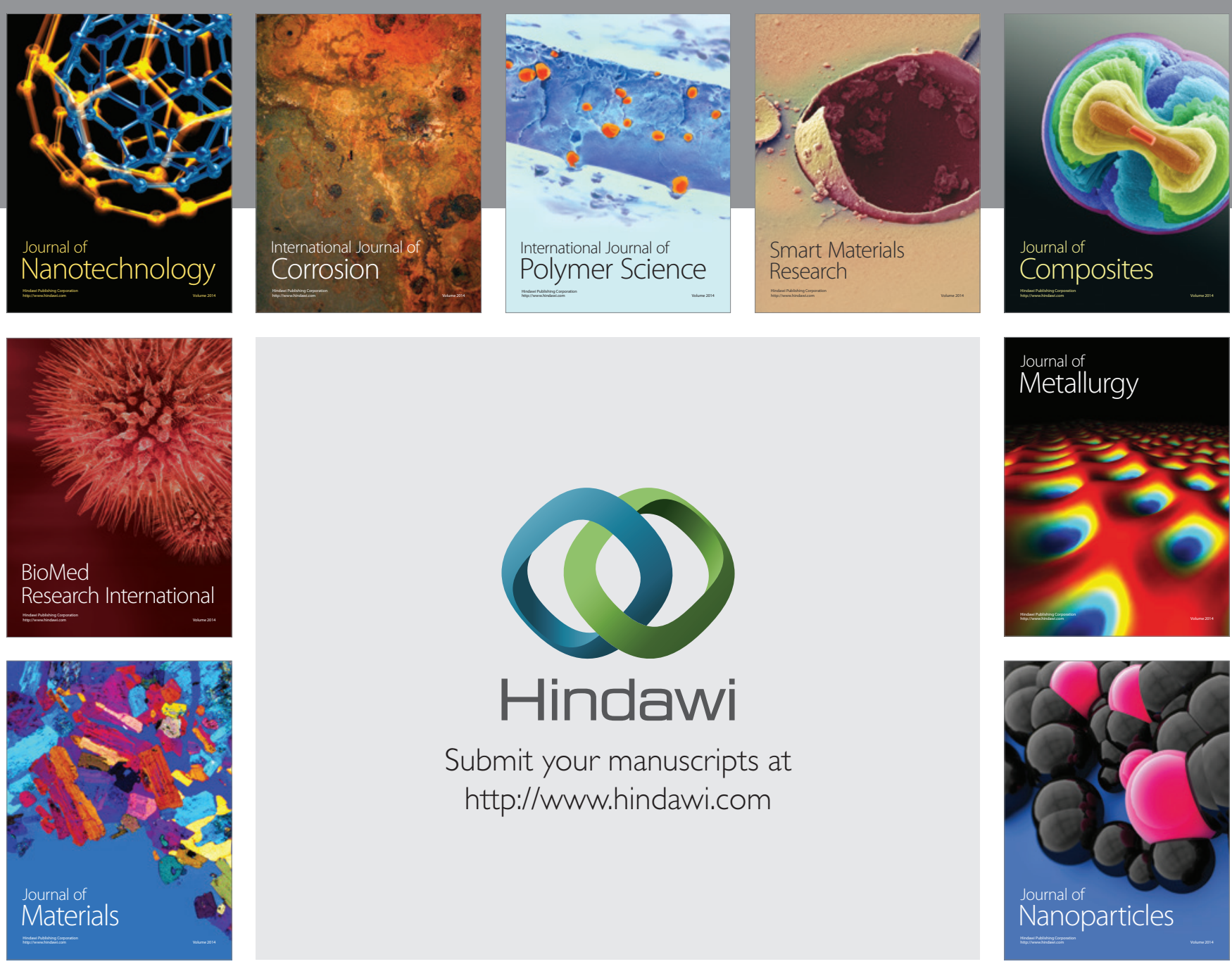

Submit your manuscripts at http://www.hindawi.com
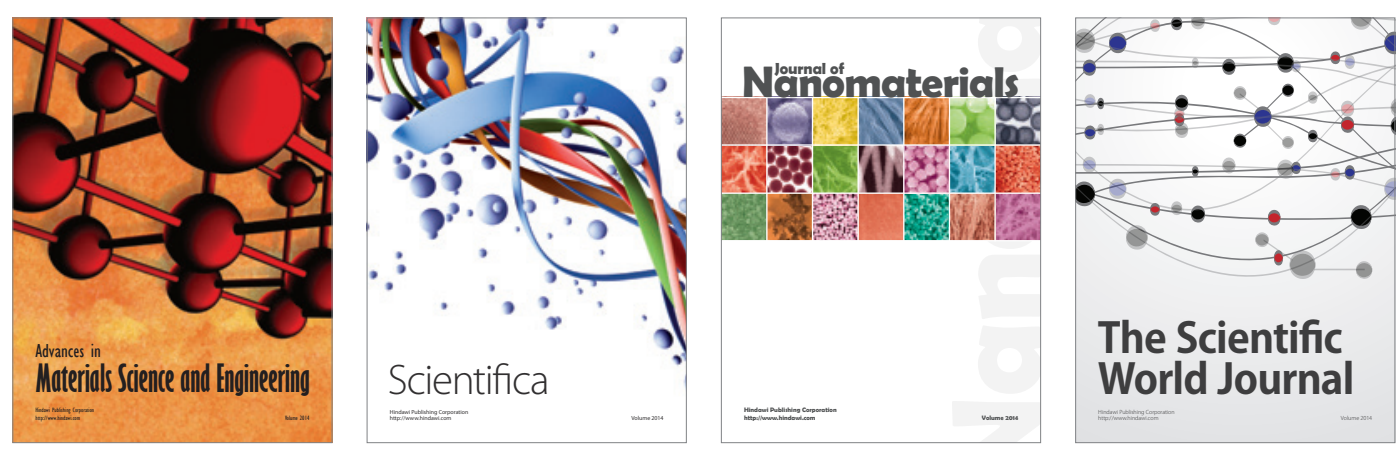

\section{The Scientific World Journal}
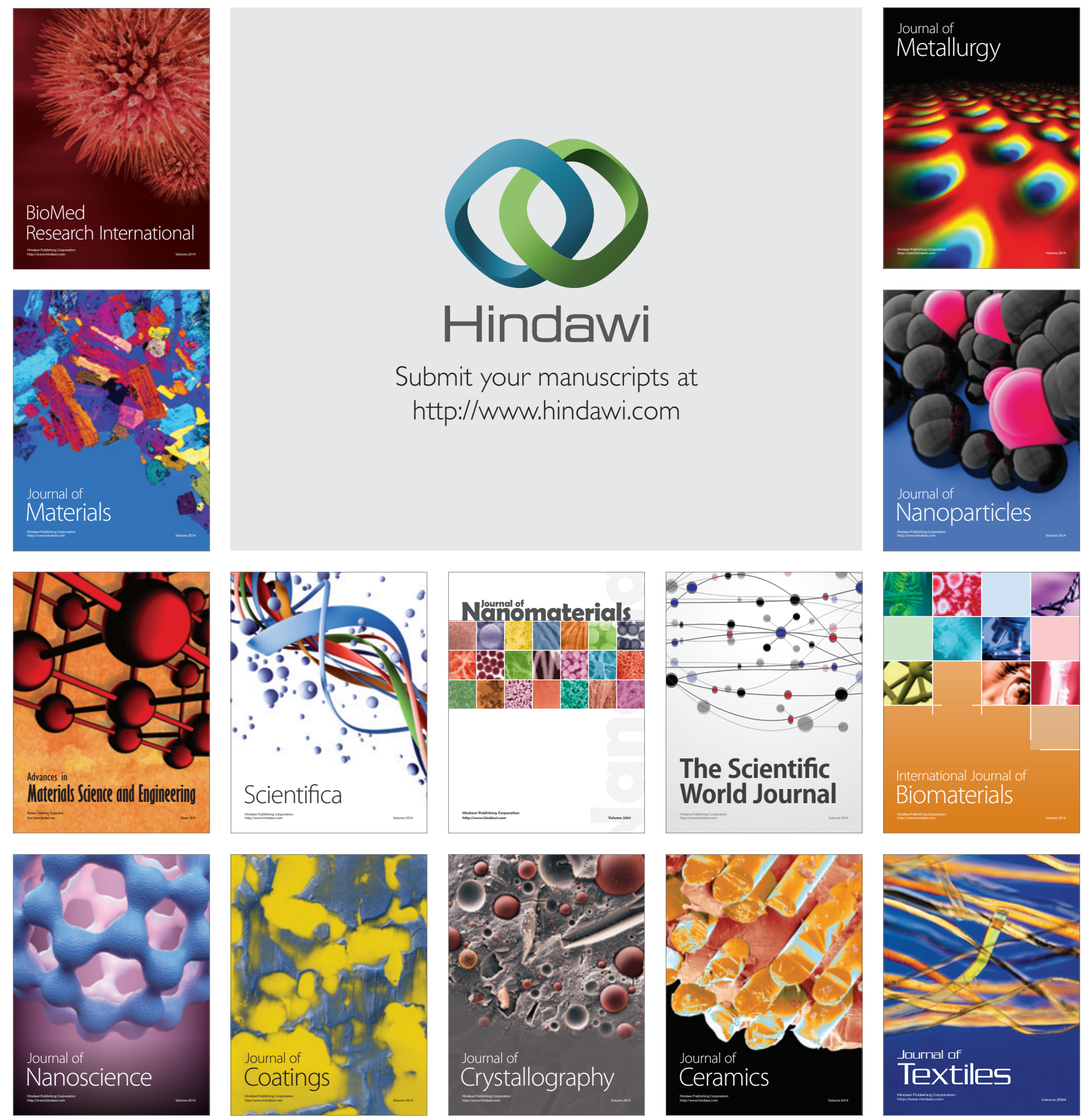